DOCTRINA

\title{
Implementación de las tecnologías de la información y la comunicación en los consultorios jurídicos en Colombia: Una aproximación al estado de la cuestión
}

\author{
Implementation on information and communication technologies in legal clinics \\ in Colombia: An approach to the state of the matter
}

\author{
Juliana Guevara Flórez \\ Institución Universitaria de Envigado, Colombia
}

Carlos Eduardo Uc Ríos

Universidad Autónoma de Campeche, México

\begin{abstract}
RESUMEN Las tecnologías de la información y la comunicación (TIC) y el internet han transformado las dinámicas del mundo. No obstante, buena parte de los servicios sociales han sido ajenos a estas transformaciones. Es por eso que este artículo hace una revisión y análisis de la implementación de las TIC para la inclusión social en la prestación de servicios sociales, pasando por la administración de justicia hasta llegar a los servicios que prestan los consultorios jurídicos en Colombia, para concluir que las TIC han sido usadas de manera rudimentaria para prestar el servicio de atención legal a los usuarios y que, para su correcta implementación y aprovechamiento, hará falta una herramienta tecnológica que responda al perfil de los usuarios, sus especiales necesidades y una política pública que promueva su uso.
\end{abstract}

PALABRAS CLAVE Consultorios jurídicos, TIC, políticas públicas, inclusión social.

ABSTRACT Information and Communication Technologies (ICT) and the Internet have transformed the dynamics of the world. However, many social services have been oblivious to these transformations. That is why this article makes a review and analysis of the implementation of information and communication technologies for social inclusion in the provision of social services, through the administration of justice until reaching the services provided by legal clinics in Colombia, to conclude that ICTs have been used rudimentary to provide the service of legal assistance to users, and that for its correct implementation and use, a technological tool that responds to the profile of the users and their special needs will be needed, as well as a public policy that promotes its use. 
KEYWORDS Legal clinics, ICT, public policies, social inclusion.

\section{Introducción}

Las tecnologías de la información y la comunicación (TIC) son hoy parte del diario vivir de la mayoría de la población del planeta. Es por ello que, a través de diversas herramientas tecnológicas, se ha querido satisfacer determinadas necesidades de los ciudadanos en la prestación de servicios tanto públicos como privados. De hecho, el uso de estas herramientas es habitual en las grandes empresas, lo que ha agregado valor a los servicios que prestan; sin embargo, no ha sucedido los mismo con servicios de tipo social.

De acuerdo con diversas investigaciones, se ha advertido que las TIC, dependiendo del servicio al que estén vinculadas, cumplen una función que se ha visto materializada en la inclusión social de personas pertenecientes a grupos vulnerables de especial protección. ${ }^{1}$ Entre estos servicios se encuentra el consultorio jurídico, que de por sí tiene un alto componente asistencial, pues aquellas personas que no cuentan con los recursos financieros necesarios para contratar un abogado en Colombia pueden acudir a las sedes de las facultades de Derecho, donde funcionan los consultorios o clínicas jurídicas, para ser atendidos de manera gratuita por un estudiante de los dos últimos años de la carrera de Derecho, asesorado por un abogado de profesión, docente de la institución de educación superior a la cual esté adscrito.

Dependiendo del asunto que consulte el usuario, y de acuerdo con las competencias asignadas a los consultorios jurídicos por la Ley 583 de 2000, se decidirá si sólo se le da orientación legal o si se podrá adelantar el proceso del interés del usuario ante la jurisdicción o instancias administrativas. Es de resaltar que uno de los objetivos fundamentales de los consultorios jurídicos es promover la justicia social y, además, constituyen una herramienta que acerca a los más desprotegidos a la administración de justicia a través de la representación legal en los estrados judiciales. Así, este texto aborda, en primer lugar, cómo la implementación de las TIC se constituye en un factor determinante para la inclusión social - y la exclusión latente, en caso de no existir una política pública para su correcta apropiación-. Luego, examina cómo se han venido utilizando las TIC en la administración de justicia a nivel internacional, y cómo han sido incorporadas las herramientas tecnológicas en los sistemas judiciales, hasta

1. La Corte Constitucional Colombiana ha definido como sujetos de especial protección a aquéllos que, debido a su condición social, física o psicológica, «merecen una acción positiva estatal para efectos de lograr una igualdad real y efectiva. Así, ha considerado que entre los grupos de especial protección constitucional se encuentran: los niños, los adolescentes, los ancianos, los disminuidos físicos, síquicos y sensoriales, las mujeres cabeza de familia, las personas desplazadas por la violencia y aquéllas que se encuentran en extrema pobreza». Corte Constitucional, sentencia T-167 de 2011. 
llegar al caso particular de Colombia. Por último, se revisa cómo los consultorios jurídicos en Colombia han implementado las TIC para la prestación de sus servicios.

En las conclusiones se harán algunas observaciones sobre el desaprovechamiento de las TIC en servicios como los consultorios jurídicos de las instituciones de educación superior en Colombia, su uso "primitivo» por parte de algunas de ellas, y la necesidad imperiosa de su utilización para la diversificación, mejoramiento y ampliación de la cobertura en materia de servicios legales, así como la importancia de una política pública para la promoción de su uso.

\section{Implementación de TIC y su impacto en la inclusión social}

Antes de abordar la incorporación de las TIC en servicios como la administración de justicia o los consultorios jurídicos en Colombia, se revisarán algunos datos relacionados con la importancia del internet y la implementación de las TIC como una herramienta de inclusión social, consecuencia adyacente de los servicios prestados por el consultorio jurídico.

En el marco de un mundo cada vez más globalizado, las tecnologías de la información han jugado un papel muy importante en la sociedad. Con el surgimiento del internet en 1991, las nuevas tecnologías han llegado a utilizarse en forma regular en las actividades cotidianas. La cantidad de usuarios de plataformas tecnológicas va en aumento y, por ello, muchos servicios que otrora se prestaron de manera presencial, ahora son accesibles a través de la red.

Este impacto se ve reflejado en diferentes estudios. Un caso es el conjunto de informes Global Digital de 2020, publicados por We Are Social y Hootsuite, ${ }^{2}$ los cuales revelaron que en el mundo hay más de 4.540 millones de personas que usan el internet. Respecto de la industria móvil, el informe anual ${ }^{3}$ de GSMA Mobile Economy ${ }^{4}$ contiene datos tecnológicos, socioeconómicos y financieros sobre su estado, incluyendo pronósticos hasta el año 2025. De acuerdo con el estudio, para finales de 2017 había más de 5.000 millones de personas conectadas a servicios de telefonía móvil. Sumado a esto, el estudio vaticina que para el año 2025, el número de suscriptores únicos a estos servicios llegará a 5.900 millones, pasando del $66 \%$ al $71 \%$ de la población mundial. Los usuarios de teléfonos celulares con internet, que a 2017 se encon-

\footnotetext{
2. Simon Kemp, «Digital in 2020: 3.8 billion people use social media», We Are Social, 30 de enero de 2020, disponible en https://bit.ly/37gJx4U.

3. «The Mobile Economy Report 2018», GSMA, disponible en https://bit.ly/3lWwU2R.

4. El Groupe Speciale Mobile (GSMA) representa los intereses de los operadores móviles en todo el mundo, por lo que une a casi 800 operadores con más de 300 empresas en el ecosistema móvil más amplio, incluidos fabricantes de dispositivos, compañías de software, proveedores de equipos y compañías de internet, así como organizaciones en sectores industriales adyacentes. «About us», GSMA, disponible en https://www.gsma.com/aboutus/.
} 
traba en una cifra aproximada de 3.300 millones, llegarán a 5.000 millones para el 2025, lo que equivale a un incremento del $43 \%$ al $61 \%$ de la población mundial. Además, el estudio prevé que el internet de las cosas crecerá más de tres veces, pasando de 7.500 millones de conexiones registradas hasta 2017 a 25.000 millones para 2025 . Estas cifras dan cuenta de la vertiginosa e imparable penetración de las tecnologías de la información y el internet en la vida cotidiana.

Es evidente que las TIC han transformado la manera en que se comunican los seres humanos. De las formas más cotidianas de comunicación, como la radio, la televisión y la telefonía, se ha pasado al uso de plataformas virtuales que utilizan computadores, teléfonos móviles e internet para los trámites y diligencias que se llevan a cabo a diario. Es el caso de transacciones bancarias, pago de facturas, expedición de certificados, derechos de petición ${ }^{5}$ y demás solicitudes que se pueden hacer a través de portales virtuales dispuestos para dichos propósitos.

El uso del internet es parte del estilo de vida de una gran cantidad de personas. Pasan horas frente a un dispositivo electrónico, se comunican a través de correos electrónicos y chats: «Así, contar con un computador y acceso a internet se les hace imprescindible, de allí el esfuerzo de familias y Estado por proveer de estos recursos tecnológicos» (Silva y Romero, 2014). A esto se debe agregar la educación virtual como uno de los modelos de enseñanza y aprendizaje de mayor tendencia en la actualidad.

Así pues, «las tecnologías de la información y la comunicación han sido usadas con el fin de promover la inclusión social de manera que quienes por diferentes factores no pueden acceder a diversos servicios tanto públicos como privados, encuentren en las TIC una herramienta que facilite dicho acceso» (Guevara Flórez, 2020: 57). De acuerdo con Vallejo, la inclusión social busca promover la equidad e igualdad, sin importar la raza, sexo, filiaciones políticas o ideológicas, características sociales o económicas. La inclusión «supone el respeto por la dignidad de las personas y por consiguiente de su libertad y determinación, así como el reconocimiento de sus plenos derechos» (Vallejo, 2012: 11).

De ahí que diferentes autores hayan abordado el tema de las TIC como herramientas de inclusión social, desde diferentes perspectivas. Es el caso de Sánchez Duarte, quien dice:

Las TIC deben aprovecharse para el desarrollo integral de una comunidad. Una visión integral de desarrollo no implica que se apunte sólo hacia el crecimiento económico sino, sobre todo, que impulse el potencial humano en sus diferentes dimensiones para afianzar así la prosperidad económica pero con equidad, y el fortalecimiento democrático con transparencia y justicia social (Sánchez Duarte, 2008: 157).

5. El derecho de petición en Colombia es el que tiene toda persona a «presentar peticiones respetuosas a las autoridades» en los términos que la ley señala (Ley 1.755 de 2015, artículo 1). 
Asegura la autora que las TIC deben ser usadas para el beneficio social de los seres humanos, y es lo que ocurre cuando se ponen recursos pedagógicos innovadores a disposición de la educación. No obstante, se resalta que la inclusión de TIC en diferentes contextos debe estar precedida por una sensibilización y condiciones adecuadas que posibiliten el acceso con equidad, de manera que se favorezca el desarrollo social. Propone Sánchez Duarte que las TIC se incorporen en actividades cotidianas que permitan potenciarlas, y que sean una estrategia de comunicación coherente, de manera que sirvan para resolver y facilitar procesos en lugar de obstaculizarlos.

Sumado a esto, advierte Sánchez Duarte (2008: 157) que «el acceso a las TIC no soluciona con su sola presencia el problema del desarrollo humano, sino que es necesario ir más allá de la conectividad, promoviendo el acceso equitativo, uso y apropiación social de los recursos disponibles». Continúa indicando que el uso de las TIC puede presentar ciertas amenazas o riesgos, como el aumento de desigualdades, la imposición de contenidos y cultura, abundancia descontrolada de información, aislamiento y fragmentación cuando los usuarios limitan su espectro de comunicación al cibernético. Lo anterior, contrastado con aspectos positivos del uso de las TIC, como el acceso fácil y ágil a información actualizada con origen en diferentes lugares del globo, el aumento de formas de comunicación novedosas y veloces, y nuevas formas de alianzas, redes y trabajo colaborativo.

Lo anterior es reafirmado por Rodríguez (2012: 42) cuando habla de inclusión y exclusión social producto del uso de las tecnologías de la información. Dicha exclusión se produce por factores como la desigualdad de estratos socioeconómicos, el territorio, zonas urbanas y rurales, la educación y la edad, entre otros. Son precisamente estas desigualdades sociales las que provocan una brecha digital, que marca una diferencia entre quienes tienen y quienes no tienen acceso a las TIC.

Es por esto que, de acuerdo con Rodríguez (2012: 54), cualquier iniciativa que incorpore el uso de las TIC debe evaluar las condiciones sociales de la comunidad que se pretende impactar, y se debe acompañar de políticas públicas que faciliten su incorporación, de manera que se cumpla con el objetivo de inclusión y que se atiendan las necesidades de la población a quien va dirigida. La ausencia de políticas públicas que contemplen acciones para la sensibilización de la comunidad frente a las TIC producirá la exclusión de aquéllos que tienen resistencia a su uso.

En el mismo sentido, el informe 2015 del Programa de las Naciones Unidas para el Desarrollo (PNUD), ${ }^{6}$ respecto de los Objetivos de Desarrollo del Milenio, concuerda con las anteriores afirmaciones, en el sentido de que si bien en Colombia en particular han aumentado los niveles de conectividad a las TIC, el crecimiento tecnológico se concentra en las grandes urbes, mientras que es más evidente la brecha digital en

6. Selim Jahan, «Informe de 2015 sobre los Objetivos de Desarrollo del Milenio», PNUD Colombia, 6 de julio de 2015, disponible en https://bit.ly/2H9VtKT. 
zonas rurales, junto con la necesidad de promover políticas públicas que permitan el acceso al uso de las tecnologías de la información y la comunicación y el cierre de brechas sociales. Pérez y Sarrate (2011: 238) coinciden en las barreras que se pueden presentar para la cohesión social con el uso de las TIC, y por eso insisten en que «facilitar el acceso de los colectivos más vulnerables es decisivo para su integración, participación e inserción social con los mismos derechos que el resto de los ciudadanos».

No obstante, no se deja de lado la capacidad humanizadora de las TIC para equilibrar las diferencias sociales. Por eso, «es preciso realzar la importancia que tiene la accesibilidad para todas las personas, como manifestación y promoción de la inclusión y la no discriminación» (Guevara Flórez, 2020: 59). Si bien no todas las personas están familiarizadas con los avances tecnológicos que se dan en el marco de las TIC, adquirir estos conocimientos propiciará la eliminación o disminución de los obstáculos de la brecha digital.

Para el caso particular de Colombia, Flórez Buitrago, Ramírez y Ramírez (2016: 56) manifiestan que «el acceso a las TIC en Colombia es limitado y excluyente, pues depende de factores netamente económicos, de infraestructura y acceso a redes». La investigación adelantada por los autores indica, por ejemplo, que las TIC deben ser incorporadas en la vida diaria de los adolescentes con discapacidad, puesto que son elementos que facilitan su inclusión social, promueven la participación y los procesos de formación, y su no utilización por parte de esta población produce segregación, exclusión social y una brecha digital que los aparta de la sociedad. Sobre este punto, también se ha dicho que:

La demanda y utilización de soluciones tecnológicas en relación a personas con discapacidad va creciendo cada vez a una velocidad mayor, como corresponde a una sociedad desarrollada. Esta tecnología debe adaptarse fácilmente a circunstancias y usuarios variados a fin de compensar limitaciones, potenciar funciones y propiciar actuaciones con el fin de prestar un mejor servicio a la diversidad (Pérez y Sarrate, 2011: 246).

Si bien la inclusión de las TIC en la vida cotidiana está en un constante y vertiginoso ascenso, no se puede perder de vista que pueden ser tanto un factor de inclusión como de exclusión. Por esto, y con el fin de que las herramientas tecnológicas sean un instrumento que promomueva la inclusión social, se hace necesario la promoción de políticas públicas que incluyan un trabajo de sensibilización en la comunidad que va a ser impactada.

En este contexto, el Gobierno presentó en 2018 el proyecto de ley para la modernización de las TIC en Colombia, que finalmente se convirtió en la Ley 1.978 de 2019. La exposición de motivos del proyecto expresó la necesidad urgente de reducir la brecha digital para las personas de menos recursos. Mediante un estudio, se estableció que en el país existen 30,3 millones de conexiones a internet, por lo que una de 
cada dos personas tiene acceso a internet móvil o fijo. Más preocupante resulta que la brecha digital sea tan evidente eomn los estratos socioeconómicos más bajos, ya que mientras en el estrato 6 la penetración del internet es del 98\%, en el estrato 1 solo representa el $21,7 \%$. $^{7}$

Reconociendo la importancia que reviste la implementación de políticas públicas para la inclusión social mediada por las TIC, el Gobierno colombiano implementó la política «El futuro digital es de todos» en la agenda 2018-2022 del presidente Iván Duque Márquez, de la cual uno de los principales pilares es la inclusión social digital, que busca la apropiación de la tecnología de manera equitativa. ${ }^{8}$ Esta política tuvo algunos avances, como el Centro de Relevo, consistente en una plataforma para personas sordas y oyentes que permite que se comuniquen entre sí usando tabletas, computadores y teléfonos celulares, con la ayuda de intérpretes virtuales con formación en lengua de señas; ConVerTIC, que busca promover la autonomía de las personas con discapacidad visual con la posibilidad de descargar softwares para la lectura o la ampliación de pantallas; y Cine para Todos, que hace accesibles las películas a personas con limitaciones visuales, auditivas o ambas. ${ }^{9}$

Con todo, tras el advenimiento de la crisis global provocada por el covid-19 y el estado de emergencia social y económica declarado por la Presidencia de la República (Decreto 417 de 2020), se ha evidenciado el poco desarrollo que ha tenido dicha política, sobre todo en los sectores más vulnerables de la sociedad colombiana. El programa para la masificación del internet para personas de estratos 1 y 2, viviendas de interés social y bajos puntajes en el Sisbén ${ }^{10}$ ha sido insuficiente para hacer frente a la situación actual del país.

En el sector educación, sólo por citar un ejemplo, los niños y jóvenes en estado de pobreza pertenecientes a colegios públicos son quienes han recibido el impacto más fuerte producto de la crisis: el acceso a internet es limitado, no cuentan con los equipos electrónicos para acceder a las clases y, en la mayorías de las veces, se hace un seguimiento a distancia de los procesos de enseñanza y aprendizaje por vía telefónica o, en el mejor de los casos, a través de correos electrónicos, lo que en consecuencia

7. “"El futuro digital es de todos”: Conozca el proyecto de ley de modernización del sector TIC que beneficia a todos los colombianos», Ministerio de Tecnologías de la Información y Comunicaciones, disponible en https://bit.ly/2H9VQVN.

8. «"El futuro digital es de todos": La nueva política TIC», Ministerio de Tecnologías de la Información y Comunicaciones, 31 de agosto de 2018, disponible en https://bit.ly/3kZ5WqY.

9. «Inclusión TIC», Ministerio de Tecnologías de la Información y Comunicaciones, disponible en https://bit.ly/3mZVqBH.

10. «El Sisbén es el Sistema de Identificación de Potenciales Beneficiarios de Programas Sociales que, a través de un puntaje, clasifica a la población de acuerdo con sus condiciones socioeconómicas». «¿Qué es el Sisbén», Sisbén, disponible en https://bit.ly/36jksFN. 
afecta de manera significativa la calidad académica. ${ }^{11}$ También se han visto afectados la administración de justicia y los servicios legales gratuitos que ofrecen los consultorios jurídicos, por lo que se analizará dicha cuestión más adelante.

La actual crisis no ha hecho más que demostrar el atraso sistemático de Colombia en materia de TIC y el efecto negativo que ha tenido en la inclusión social para personas en estado de pobreza. En este momento, de una población aproximada de 50 millones de habitantes, más de 23 millones no cuentan con los medios económicos para acceder al internet o no tienen sistemas de conectividad adecuados debido a su localización en zonas rurales, apartadas de los cascos urbanos..$^{12}$ Sumado a esto, las administraciones municipales, departamentales y nacionales, encargadas de responder las peticiones de los ciudadanos, no están atendiendo de manera presencial, por lo que remiten a los sitios web de las entidades, a las que no tiene acceso la mitad de la población.

Esto, por lo demás, pone en evidencia que no se trata tan sólo de la creación de políticas públicas para la incorporación de las TIC. Se trata de su efectiva implementación para la ampliación de la cobertura, destinando los recursos económicos necesarios para que las personas en mayor estado de vulnerabilidad, por su condición socioeconómica y ubicación geográfica, puedan acceder a todos los servicios públicos a través de las plataformas digitales.

\section{TIC en la administración de justicia}

El consultorio jurídico «es por excelencia la proyección social de las facultades de Derecho en Colombia, que, en su afán por alcanzar la justicia social como uno de sus principales objetivos, busca tener un gran impacto en la resolución de conflictos de la comunidad que atienden» (Guevara Flórez, 2020: 64). Esto se puede dar, bien sea a través de consultas que resuelven los estudiantes con el asesoramiento de abogados titulados, que representan a los usuarios en procesos judiciales de su competencia; o por medio de los centros de conciliación adscritos a los consultorios de las facultades, en los cuales pueden actuar como conciliadores tanto estudiantes de Derecho como abogados docentes (Decreto 1.829, de 2013).

Se puede decir que uno de los mecanismos que facilitan el acceso a la administración de justicia se encuentra en el servicio social y asistencial que prestan los consultorios jurídicos adscritos a las facultades de Derecho en Colombia, consistente en la representación legal de personas de bajos recursos ante los despachos judiciales, los

11. Camila Taborda, «No puede cumplirse el modelo de alternancia para que los niños vuelvan al colegio», El Espectador, 25 de mayo de 2020, disponible en https://bit.ly/315Kq3X.

12. «Día internacional del internet: ¿Cómo está Colombia en conectividad?», Semana, 17 de mayo de 2020, disponible en https://bit.ly/2HLjoQY. 
que materializan el mencionado derecho de los ciudadanos que están en condiciones de vulnerabilidad por su situación económica, entre otras circunstancias. De acuerdo con la Corte Constitucional de Colombia, ${ }^{13}$ la administración de justicia es un derecho que consiste en:

la posibilidad reconocida a todas las personas residentes en Colombia de poder acudir en condiciones de igualdad ante los jueces y tribunales de justicia, para propugnar por la integridad del orden jurídico y por la debida protección o el restablecimiento de sus derechos e intereses legítimos, con estricta sujeción a los procedimientos previamente establecidos y con plena observancia de las garantías sustanciales y procedimentales previstas en las leyes (sentencia T-283, de 2013).

Ahora bien, diversos autores se han referido a la implementación de las TIC para los servicios relacionados con la administración de justicia. A nivel internacional, existen diferentes referentes a los que se hará alusión a continuación. Luego, se abordará lo que en la actualidad contempla la normatividad colombiana: qué vincula la incorporación de las tecnologías de la información a la administración de justicia, qué se encuentra implementado hoy y, por último, qué medidas se han tomado en el marco de la declaratoria de la emergencia social y económica en el país como consecuencia del covid-19.

Ricardo Lillo Lobos (2010) señala diferentes beneficios al incorporar nuevas tecnologías en los sistemas judiciales, como: i) los funcionarios judiciales podrán economizar tiempo; ii) se promoverá la transparencia; iii) las instituciones estatales podrán acceder con más facilidad a la información y en menos tiempo; iv) los usuarios del sistema judicial podrán relacionarse directamente con los órganos con funciones judiciales; y v) se promoverá la eficiencia y eficacia, entre otros.

El autor resume estos aspectos en dos grandes objetivos: i) «Mejorar la gestión y desempeño», en lo que incluye la gestión y tramitación de procesos, la calidad de la información producto de las audiencias y la simplificación la toma de decisiones; y ii) «mejorar el acceso a la justicia» (Lillo Lobos, 2010: 119), a través del acceso a la información y servicios. Indica Lillo Lobos que la incorporación de estos sistemas debe responder no sólo a la normatividad y al contexto cultural, sino también a «los principios democráticos y del derecho internacional de los derechos humanos» (Lillo Lobos, 2010: 119), lo cual implica un avance en la modernización de la justicia y, a su vez, en la promoción de derechos humanos, aspecto fundamental de esta investigación.

Es así como el autor refiere algunas de las plataformas que son usadas en diferentes países que facilitan la gestión y tramitación de procesos. Entre ellos se encuentran:

13. Órgano de cierre en materia constitucional en Colombia. Sus funciones están consagradas en el artículo 241 de la Constitución Política de 1991. 
- Finlandia: Cuenta con el sistema Toumas, que contiene las singularidades de las partes, la naturaleza de la acción, la cuantía, los documentos que vinculan a las partes y el resultado de las audiencias.

- Países Bajos: El Ministerio de Justicia tiene un sistema llamado Justienet, al que pueden acceder tanto usuarios externos como miembros de tribunales y el Ministerio Público. Cuenta con una intranet exclusiva para los tribunales, llamada INTRO (Intranetvoor de rechterlijke organisatie, «intranet para la organización judicial»), y la del Ministerio Público, denominada OMtranet (Openbaar Ministerie Intranet, «intranet de la Fiscalía»).

- Portugal: Dispone del sistema llamado H@bilus, que puede ser utilizado por todas las partes, incluidos abogados, funcionarios judiciales, jueces, fiscales y procuradores. Además, las actuaciones pueden ser registradas a través del portal CITIUS y las notificaciones se hacen de manera electrónica.

- Israel: Cuenta con un sistema llamado NGCS (Next Generation Court System, «sistema de corte de próxima generación»), que permite subir los documentos y comunicaciones judiciales. Una de las ventajas de este software es que los interesados pueden hacer peticiones y recibir respuestas a través de él y, además, se podrán actualizar los procesos por las partes intervinientes.

- Reino Unido: Cuenta con el sistema XHIBIT, que funciona para los procesos penales y está conectado con tribunales, abogados, fiscalía, la Policía y el servicio penitenciario.

- Singapur: La Corte Suprema tiene el EFS (Electronic Filing System («sistema de archivo electrónico»), en el que se puede acceder a todo el expediente de manera digital. Quienes no tienen computador pueden ingresar al sistema en equipos ubicados en el edificio del alto tribunal, obtener copias del expediente previa autorización y enviar de forma automática escritos a las partes a través de correo electrónico.

Por otro lado, asegura el autor que, dependiendo de la tradición a la que se adscriba el sistema judicial de determinado país, las plataformas se utilizarán en mayor o menor medida. ${ }^{14}$ No obstante, es de anotar que los sistemas que han tenido mayor tradición escritural tienden a implementar el sistema oral con el objetivo de darle más celeridad a la tramitación de los procesos.

Afirma Lillo Lobos (2011: 130) que la implementación de TIC busca «superar las barreras de acceso a la justicia», al mejorar la relación entre las instituciones y los

14. Los sistemas tradicionales son el civil law, con una tradición escrita, y el common law, de tradición oral. 
usuarios; de la misma manera, asegura que la implementación de TIC ha sido más prolífica en la rama Ejecutiva del poder público que en la rama Judicial, lo que tiene absoluta vigencia en Colombia. Ejemplo de esto son los trámites electrónicos que se pueden hacer ante la administración, en los que la comunicación es interactiva y no meramente informativa.

Finaliza el autor exponiendo que la implementación de las TIC en un sistema de justicia en América Latina debe tener en cuenta su contexto, toda vez que, si bien se ha procurado la implementación de las tecnologías a través de la normatividad, en la práctica dicha incorporación ha sido débil. Además, indica que si la justicia de determinado país respeta derechos humanos como el debido proceso, se facilitará la eficiencia y eficacia del sistema.

A la terminación del seminario sobre «Tendencias Recientes y Buenas Prácticas en la aplicación de Tecnologías Digitales al Proceso Judicial», celebrado en abril de 2011 en la Ciudad de México, se elaboró un documento de conclusiones que - para lo que compete a este texto- tiene mucha relevancia, toda vez que estos principios sirven de parámetros para el diseño, desarrollo, ejecución y producción de esta investigación. Dichos apuntes se pueden resumir de la siguiente manera:

- La tecnología reviste gran importancia para el mejoramiento de los sistemas judiciales. Es por esto que los cambios que se gestionen en el marco de aquélla deben tener objetivos claramente definidos, atender necesidades particulares, tener actividades debidamente planificadas y se debe hacer seguimiento constante.

- Las transformaciones tecnológicas que se surtan deben responder a las necesidades del contexto que atenderá.

- La utilización de las tecnologías de la información y la comunicación debe propender por la garantía de derechos propios de los procesos judiciales, como publicidad, presunción de inocencia, transparencia, contradicción y acceso a la información.

- La incorporación de las TIC en los sistemas judiciales deberá garantizar la protección de los datos personales de los usuarios.

- La implementación de nuevas tecnologías en los sistemas judiciales debe procurar el aumento en la cobertura, la eficiencia y la calidad del servicio.

- Antes de la transformación, se deberá hacer una evaluación que procure determinar cuáles serían los impactos relacionados con aspectos como el valor económico y los beneficios.

- «Las políticas de difusión y el acceso a la información judicial deben basarse en el principio de máxima divulgación y el interés público comprometido». 
(Caballero, De Gràcia y Hammergren, 2011: 278).

- Los sitios web deberán coadyuvar, entre otros a: i) aumentar el uso de servicios digitales facilitando el acercamiento de los usuarios, con el fin de disminuir la necesidad de su presencia física; ii) incrementar servicios interactivos en la plataforma web implementando espacios de participación; y iii) potenciar la prestación de servicios rápidos, seguros, accesibles y eficaces.

Estos aspectos resultan relevantes, pues es razonable tenerlos en cuenta para la implementación de herramientas tecnológicas que persigan la prestación de servicios jurídicos mediados por las TIC.

Ahora bien, Jiménez Gómez (2014) señala que, a diferencia de las entidades e instituciones administrativas del Estado, la justica se ha quedado atrás en lo que se refiere a la implementación de herramientas innovadores a través de las TIC. En este sentido, dicha incorporación se podría encontrar frente a dos escenarios: uno de mejora continua, y otro de reingeniería. En todo caso, el fin siempre deberá ser acercar a la ciudadanía para que tenga una activa participación en la administración de justicia.

El autor manifiesta que, para el caso de la justicia, se deberá procurar la mejora en la prestación de los servicios y, aunado a ello, la capacitación y adiestramiento en el uso de herramientas tecnológicas para todos los usuarios del sistema. Incluso, se deberá pensar en la inserción de nuevos actores que faciliten la implementación de estas innovaciones y procuren la mejora continua de los procesos.

Una mirada muy particular tiene Sourdin (2015: 1-2) cuando habla de la inclusión de las TIC en los sistemas de justicia. Relaciona la autora tres niveles de inclusión de la tecnología: un nivel básico que apoya y aconseja a las personas involucradas en el sistema de justicia, llamado tecnología de apoyo; un segundo nivel, en que las tecnologías reemplazan actividades y funciones llevadas a cabo por humanos, llamado tecnología de reemplazo; y un tercer nivel, llamado tecnología disruptiva, en que los procesos cambian en forma significativa e influyen en la manera en que los jueces trabajan y administran justicia.

Con la tecnología de apoyo, los sistemas de justicia hacen uso de redes sociales como Facebook, Twitter o Youtube y sitios web para comunicarse con los usuarios, además de aplicaciones para quienes no disponen de un computador, pero sí de teléfonos móviles inteligentes. Estas herramientas se caracterizan por ser meramente informativas.

La tecnología de reemplazo es aquélla que puede sustituir ciertas interacciones entre las partes de un proceso judicial. Por ello, es utilizada en la solución alternativa de conflictos para reemplazar las audiencias cara a cara por diligencias a través de videoconferencias. Por ejemplo, en Australia y algunos países europeos, este tipo de tecnologías se utiliza mucho con el comercio electrónico y esquemas basados en el consumidor. En los sistemas de justicia se usan expedientes electrónicos, videoconferencias 
y aplicaciones que funcionan como un complemento de muchas jurisdicciones.

Para finalizar, la tecnología disruptiva está relacionada con inteligencia artificial legal para desarrollar alternativas de procesos e impulsarlos. Un sistema de este nivel sería de consultoría experta para la toma de decisiones; por ejemplo, el sistema haría preguntas al usuario y daría varias soluciones o respuestas a la cuestión. Si bien existen ventajas relacionadas con las actividades de clasificación y análisis que puede hacer un software ahorrando tiempo y costos, no se puede dejar de lado que a este nivel se presentan desventajas, como la amenaza a la independencia de quien decide, la ausencia de un elemento humano que pueda ser requerido en circunstancias especiales y el riesgo de reemplazar normatividad debido a la aplicación automatizada, entre otros.

En lo que atañe a Colombia, la administración de justicia es una atribución del Estado consagrada en el artículo 229 de la Constitución Política. Es por eso que en el Conpes 3.072 de 2000, el Estado colombiano promueve el uso de las TIC para brindar el acceso equitativo a la justicia; y, en consecuencia, la Ley 1.564 de 2012, el Código General del Proceso, incorpora al ordenamiento jurídico el Plan de Justicia Digital.

El artículo 103 de la precitada ley advierte que se deberá procurar «el uso de las tecnologías de la información y las comunicaciones en la gestión y trámite de los procesos judiciales, con el fin de facilitar y agilizar el acceso a la justicia, así como ampliar su cobertura». De la misma manera, la normatividad establece que se implementarán las herramientas para hacer posible los litigios en línea y los expedientes electrónicos, los cuales empezarán a funcionar en forma paulatina.

Ejemplo de esto es la ya común notificación de providencias a través de medios electrónicos que contempla la Ley 1.437 de 2011, el Código de Procedimiento Administrativo y de lo Contencioso Administrativo, que entró en vigor el 2 de julio de 2012. No obstante, no se debe perder de vista que, en la práctica, esto es solo una modalidad para informar a las partes interesadas sobre actuaciones que ha surtido el juez en el proceso, es decir, no implica que el interesado no deba acudir personalmente al juzgado para conocer el contenido de las actuaciones. En pocas palabras, en la actualidad las notificaciones electrónicas son medios para informarse, mas no para interactuar con el operador jurídico.

De hecho, cuando un usuario ingresa a la página de la rama Judicial para la consulta de procesos, ${ }^{15}$ por lo general sólo aparece información que enuncia sus actuaciones; en forma esporádica se encuentran los documentos de las actuaciones en la plataforma. Esto sin mencionar ciudades tan importantes como Sincelejo y los despachos de pequeños municipios, que no han implementado dicho sistema, lo que hace obligatorio que las partes interesadas se acerquen a los despachos judiciales so pena

15. «Consulta de procesos», Rama Judicial del Consejo Superior de Colombia, disponible en https:// bit.ly/3nXU4bo. 
de vencimiento de términos, lo cual trae posibles consecuencias, como la terminación anormal de procesos por desistimiento tácito.

La Resolución 828 de 2015 del Ministerio de las Tecnologías de la Información y las Comunicaciones, por medio de la cual «se adopta el Plan Estratégico Sectorial e Institucional del Ministerio de las Tecnologías de la Información y las Comunicaciones para el período 2014-2018», establece en el punto 5.3.3 que las TIC son una herramienta que promueve «la transparencia, eficiencia y acceso a la justicia» $y$, por tanto, se propone desarrollar un plan que busca en definitiva alcanzar tres objetivos: i) desarrollar «aplicaciones de alto impacto como el expediente judicial en línea, el sistema unificado de gestión judicial y el registro nacional de abogados»; ii) crear la infraestructura tecnológica para que todos los actores del sistema de justicia puedan interactuar; y iii) capacitar a los operadores jurídicos en la utilización de las TIC fomentando «una cultura de cero papel». ${ }^{16}$ Todo esto, retomando lo que ya había establecido el Plan Nacional de TIC 2008-2019.

A pesar de los ya mencionados intentos de generar cambios a través de la transformación de la normatividad interna nacional en el sector justicia, sólo hasta el 12 de diciembre de 2018 se firmó un memorando de entendimiento entre el Gobierno y la rama Judicial para modernizar el sistema de justicia poniendo en marcha un plan piloto que busca la incorporación del expediente electrónico judicial en cinco clases de procesos, como nulidad de propiedad industrial, asuntos tributarios, «acción pública de inconstitucionalidad, trámites de selección, revisión y acción de tutela y exequatur». ${ }^{17}$ No obstante, los resultados aún están por verse.

Es de resaltar que la Personería de Medellín, ${ }^{18}$ en su afán por facilitar trámites judiciales que normalmente se hacen en sus instalaciones de manera presencial, implementó desde 2016 la acción de tutela en línea, ${ }^{19}$ solicitud que es revisada por un abogado con el fin de que cumpla con todos los requisitos que estipula la ley. «Este

16. Resolución 828, del 11 de mayo de 2015, Ministerio de Tecnologías de la Información y las Comunicaciones, p. 31, disponible en https://bit.ly/2Hciixz.

17. «Gobierno y rama Judicial le apuestan a la transformación de la justicia con el piloto "Expediente Electrónico Judicial”», Ministerio de las Tecnologías de la Información y Comunicaciones, 12 de diciembre de 2018, disponible en https://bit.ly/3cN40xy.

18. «Son un ente del Ministerio Público que ejerce, vigila y hace control sobre la gestión de las alcaldías y entes descentralizados; velan por la promoción y protección de los derechos humanos; vigilan el debido proceso, la conservación del medio ambiente, el patrimonio público y la prestación eficiente de los servicios públicos, garantizando a la ciudadanía la defensa de sus derechos e intereses». «Vigilancia de la conducta oficial», Personería de Santiago de Cali, disponible en https://bit.ly/33e $7 \mathrm{tU}_{2}$.

19. El artículo 86 de la Constitución Política establece que «toda persona tendrá acción de tutela para reclamar ante los jueces, en todo momento y lugar, mediante un procedimiento preferente y sumario, por sí misma o por quien actúe a su nombre, la protección inmediata de sus derechos constitucionales fundamentales, cuando quiera que éstos resulten vulnerados o amenazados por la acción o la omisión de cualquier autoridad pública». 
mecanismo permite que personas que incluso no viven en la ciudad puedan solicitar el apoyo jurídico que presta la Personería en esta materia» (Guevara Flórez, 2020: 72). No obstante, una vez se accede a la página, ésta contiene largos formularios que, para quien no es un usuario asiduo de medios electrónicos, pueden resultar muy engorrosos. ${ }^{20}$

En lo concerniente a la Declaratoria de Emergencia Económica, Social y Ecológica, el Decreto Legislativo 491 de 2020 del Ministerio de Justicia y del Derecho estableció que todas las ramas del poder público y organismos estatales prestarán sus servicios bajo la modalidad de trabajo en casa, utilizando para ello las tecnologías de la información y la comunicación (artículo 3).

De acuerdo con la Ley 270 de 1996, el Consejo Superior de la Judicatura es el encargado de la administración de la rama Judicial en Colombia (artículo 75); en ejercicio de dicha competencia, tal corporación ha expedido actos administrativos sucesivos prorrogando la suspensión de términos judiciales en todo el territorio nacional desde el 17 de marzo hasta el 30 de junio de 2020, lo que, en consecuencia, implicó la suspensión de la garantía de acceso a la administración de justicia contemplada en el artículo 229 de la Constitución Política, con algunas excepciones (Acuerdo PCSJA20-11567).

El Decreto Legislativo 806 de 2020 del Ministerio de Justicia y del Derecho estableció que, en lo sucesivo y por el término de dos años, se privilegiará el uso de las TIC para la prestación del servicio de acceso a la justicia, y estableció, entre otras, la obligación de dar a conocer mediante los canales de comunicación oficiales las herramientas tecnológicas que se implementarán para las actuaciones judiciales, que incluirá audiencias, diligencias, presentación de poderes, memoriales, estados y notificaciones, entre otros. El Decreto también estableció que para aquellas personas que no tengan la posibilidad de acceder a las actuaciones virtuales, los municipios, personerías y demás entidades públicas deberán facilitar su acceso.

Esta determinación conlleva problemáticas y desafíos tanto tecnológicos como prácticos para la rama Judicial, sus funcionarios y los usuarios de la administración de justicia, lo que, por demás, incluirá a los estudiantes que actúan en calidad de apoderados judiciales y usuarios de los consultorios jurídicos de las facultades de Derecho en Colombia.

El funcionamiento de la administración de justicia está a cargo del Estado (Ley 270 de 1996, artículo 5) y, por lo mismo, corresponderá a éste el suministro de los equipos tecnológicos necesarios en los más de 5.000 despachos judiciales existentes en Colombia. Esto, en virtud del artículo 57 del Código Sustantivo del Trabajo, que establece que corresponde al empleador poner a disposición de los trabajadores los elementos necesarios para la realización de sus labores.

20. Para más información, véase Personaría en Línea, disponible en https://bit.ly/2 $\mathrm{H}_{2} \mathrm{R} 2 \mathrm{lk}$. 
De acuerdo con el Decreto Legislativo 806 de 2020 y el Acuerdo PCSJA2O-1156 del Consejo Superior de la Judicatura, el 1 de julio de 2020 se reanudaron los términos judiciales. Con todo, sólo por citar algunas de las cuestiones que no resuelven ni el decreto ni el acuerdo, se pregunta: ¿cómo se solucionarán los problemas de conectividad de los municipios más alejados de las grandes urbes? ¿Qué ocurrirá con los procesos que se adelantan ante despachos judiciales que no cuentan con ningún tipo de ayudas tecnológicas para su trámite? ¿Cómo se garantizará la seguridad informática de los documentos confidenciales que hacen parte de los expedientes judiciales? ¿Cuáles serán los medios que se utilizarán para la recepción de demandas, contestaciones, memoriales, entre otros, en los despachos judiciales? ¿Los programas tendrán la capacidad suficiente para recibir archivos de gran tamaño en sus servidores? ¿Cómo se garantizará que quien envía la información es efectivamente quien dice ser cuando no se requiere la firma auténtica en el documento? (Decreto 860 de 2020, artículo 5).

Estas inquietudes tendrán que ser resueltas por el Estado y, como ya se mencionó, será su responsabilidad para la adecuada prestación del servicio. Sin embargo, de otro lado se encuentra el usuario, quien se verá en la obligación de contar con equipos tecnológicos y conectividad a internet para adelantar sus trámites judiciales. Por una parte, está el asunto de las condiciones socioeconómicas de quienes acuden a la administración de justicia para la solución de sus conflictos ¿Qué pasará entonces con quienes no tienen los medios económicos para la adquisición dispositivos electrónicos o para el pago del servicio de internet? ¿Cómo podrán hacer el envío de documentos o acceder a las diligencias virtuales? Por otra parte, está la penetración de las TIC: ¿qué ocurre con quienes no están familiarizados con el manejo de dispositivos electrónicos o el internet? ¿Se harán capacitaciones para quienes no conocen su uso?

Los que no tengan esta formación o los dispositivos electrónicos o de conectividad para hacer parte de las diligencias, ¿no podrán entonces acceder a la administración de justicia? El Estado tiene en este aspecto un desafío importante, pues si los usuarios se ven abocados a la compra de dispositivos o contratación de servicios de internet para acceder a la administración de justicia, ¿dónde queda el principio de gratuidad contemplado en el artículo 6 de la Ley 270 de 1996 ?

Ahora, suponiendo que los usuarios tuviesen solucionadas estas cuestiones, hay algunos aspectos prácticos que también representan grandes desafíos a la administración de justicia cuando se trate de la utilización de medios digitales, como lo que tiene que ver con el debate probatorio. En cuanto a las pruebas documentales, ¿ cómo se garantizará la autenticidad de los documentos o que éstos no han sido alterados cuando no se puedan valorar de manera física? En el escenario de que se enviaran los documentos a través de un mensaje de datos, el cuestionamiento sería el mismo. En cuanto a la práctica de la prueba testimonial o el interrogatorio de parte, ¿cómo 
se acreditará que quien esté declarando es quien dice ser? ¿Cómo estar seguro de que quien está declarando no está leyendo un guion o que no hay personas detrás de la cámara diciéndole qué debe o no responder, o que no está siendo intimidado o amenazado para que responda de una u otra manera? ¿Qué se hará cuando varios testigos se encuentran en la misma sala?, ¿cómo verificará el juez que el testimonio del primero no lo hayan escuchado los siguientes? Estos son inconvenientes que no se presentan en el desarrollo de la audiencia presencial. El mencionado decreto establece que se deberá garantizar el debido proceso y la contradicción, pero en tales circunstancias, ¿cómo se podrán garantizar?

Esta coyuntura supone un gran impacto para los usuarios que no cuentan con los medios económicos y las destrezas técnicas que les permita acceder a la administración de justicia, toda vez que la normatividad emitida hasta el momento por el Ministerio de Justicia y del Derecho y el Consejo Superior de la Judicatura no las resuelve. Queda entonces un largo camino que incluya acciones por parte del Estado que garanticen el derecho constitucional de acceso a la justicia, en condiciones de igualdad y equidad para todos los usuarios.

\section{Incorporación de TIC en los consultorios jurídicos en Colombia}

\section{Generalidades}

Los consultorios jurídicos tuvieron su origen en los programas de Derecho. Nacieron de la separación existente entre teoría y práctica, al buscar que el conocimiento se extendiera más allá de los muros universitarios, y han sido considerados una forma innovadora de educación en que la academia está al servicio de la comunidad. En esta modalidad de atención a la sociedad, los estudiantes de Derecho, bajo la orientación de expertos y profesores, y en algunas ocasiones en asociación con organizaciones no gubernamentales e instituciones sin ánimo de lucro, se involucran en actividades como la atención de casos de manera gratuita o pro bono a personas de escasos recursos económicos y la divulgación de los conocimientos legales necesarios para el ejercicio de los derechos de grupos de especial protección, para solucionar casos de interés público. Esta modalidad también se conoce como litigio de alto impacto (Bartoli, 2016: 15).

Por estas consideraciones, Bartoli ha planteado que los consultorios jurídicos, llamados también clínicas jurídicas, ${ }^{21}$ tienen una doble función. La primera se refiere a la naturaleza educativa y la promoción de la justicia social, mientras que la segunda

21. En inglés se conocen como legal clinics. El término clínica, de hecho, es prestado de la práctica médica, en la que los estudiantes, en conjunto con sus profesores, participan de los tratamientos de pacientes reales. La guía experta de los docentes hace de la pasantía o la residencia una experiencia segura para los estudiantes y asegura un buen estándar de servicio legal para los usuarios (Bartoli, 2016: 22). 


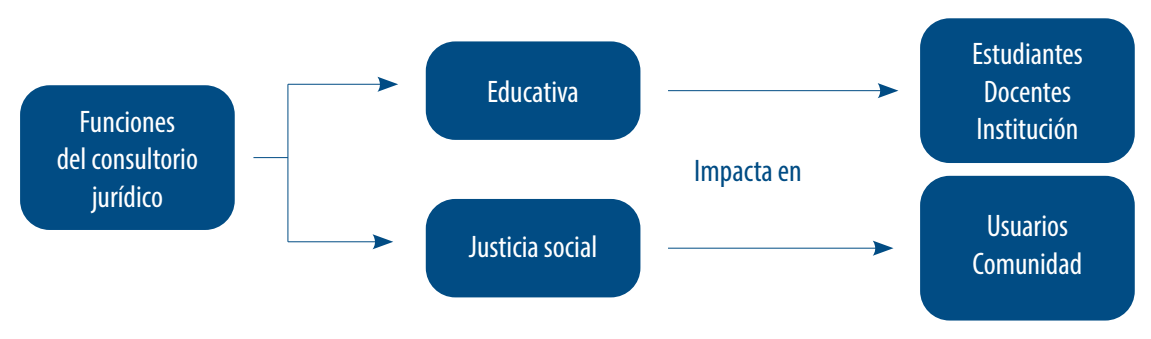

Figura 1. Funciones del consultorio jurídico. Fuente: Elaboración propia.

se refiere a los beneficios que tienen tanto estudiantes como usuarios que participan en forma activa en el consultorio jurídico (figura 1) (Bartoli, 2016: 22).

La educación de los abogados «debe perseguir el deseo de formar profesionales críticos, que cuestionen el statu quo, que propongan transformaciones que tengan repercusiones sociales, políticas y económicas de acuerdo con las realidades del entorno» (Guevara Flórez, 2020). Son los estudiantes de Derecho quienes, en el ejercicio que les permite el consultorio jurídico, pueden ser agentes de cambio social promoviendo la equidad y la inclusión de grupos que históricamente han sido discriminados por condiciones sociales, económicas y físicas, entre otras, para ir cerrando la brecha que no permite alcanzar la justicia social.

Bonilla Maldonado (2013), en referencia a lo que él llama «clínicas de derecho de interés público», ${ }^{22}$ y lo que se identifica en este texto como consultorios jurídicos, al igual que Frank (1947) y Bartoli (2016) indicaron de manera general, afirma que en América Latina estas instituciones son herramientas que sirven para contrarrestar el formalismo jurídico de la región. El autor trae el concepto de educación jurídica experiencial, tomado del modelo estadounidense, y entendido como aquél que busca la materialización tanto de los objetivos educativos como sociales durante el estudio de la carrera de Derecho, y afirma que los consultorios jurídicos de las escuelas en América Latina buscan que la inclusión de esta modalidad de enseñanza se convierta en un elemento fundamental de la educación jurídica de la región.

De acuerdo con Bonilla Maldonado (2018: 3), los tres objetivos principales de las clínicas de interés público son: i) que el derecho sea una herramienta para el cambio social y la creación de una sociedad más justa; ii) lograr un compromiso con la enseñanza experiencial; y iii) adquirir las competencias que la disciplina considera como propias. No obstante, se debe hacer énfasis en que la formación jurídica desde la ex-

22. De acuerdo con Bonilla Maldonado, se entiende por clínicas de derecho de interés público aquellos proyectos que cumplen con los siguientes requisitos: son parte de una universidad; atienden clientes reales, ya sea individuales o grupales; son gratuitos, y persiguen fines tanto pedagógicos como de justicia social. «El formalismo jurídico, la educación jurídica, y la práctica profesional del derecho en Latinoamérica» (Bonilla Maldonado, 2013: 261). 
periencia ha sido un reto en las instituciones de educación superior. En la actualidad, los programas de Derecho aún continúan siendo rígidos, ya que son resistentes al cambio tanto los docentes como la misma institucionalidad, lo que dificulta la implementación de proyectos prácticos en los programas de formación de las facultades de Derecho, como son los consultorios jurídicos.

En Colombia, el artículo 30 del Decreto 196 de 1971 -modificado por la Ley 583 de 2000 - establece que las facultades de Derecho reconocidas legalmente en Colombia deberán establecer con los estudiantes de los dos últimos años de la carrera, y bajo la asesoría de docentes, consultorios jurídicos en que los discentes actúen como abogados de usuarios de escasos recursos económicos (Ley 583), con el consultorio jurídico por lo general como la asignatura de práctica profesional de los estudiantes de Derecho. Reza el mencionado artículo que las facultades de Derecho que estén reconocidas oficialmente por el Ministerio de Educación Nacional:

organizarán, con los alumnos de los dos últimos años lectivos, consultorios jurídicos cuyo funcionamiento requerirá aprobación del respectivo Tribunal Superior de Distrito Judicial, a solicitud de la facultad interesada. Los consultorios jurídicos funcionarán bajo la dirección de profesores designados al efecto o de los abogados de pobres, a elección de la facultad, y deberán actuar en coordinación con éstos en los lugares en que este servicio se establezca.

Los estudiantes adscritos a los consultorios jurídicos de las facultades de Derecho son abogados de pobres y como tales deberán verificar la capacidad económica de los usuarios. En tal virtud, acompañarán la correspondiente autorización del consultorio jurídico a las respectivas actuaciones judiciales y administrativas.

La prestación del servicio del consultorio jurídico en ningún caso será susceptible de omisión ni homologación (Ley 583 de 2000, artículo 1).

La misma ley establece cuáles son los asuntos o materias en que los estudiantes de Derecho podrán actuar como abogados de personas con escasos recursos económicos, y hace referencia, entre otros, a los siguientes temas: procesos laborales de mínima cuantía ${ }^{23} \mathrm{y}$ conciliaciones en instancias administrativas; procesos civiles que son de conocimiento de jueces municipales en única instancia; en procesos relacionados con alimentos ante jueces de familia; además, podrán actuar como abogados de oficio en procesos disciplinarios que son de competencia de las personerías municipales y la Procuraduría General de la Nación; en procesos de responsabilidad fiscal en que la competencia le corresponde a las contralorías territoriales y la General de la República, y en los procesos administrativos sancionatorios que sean competencia de autoridades administrativas, órganos de control y entidades autónomas de naturaleza constitucional (Ley 583, artículo 1).

23. Mínima cuantía hace referencia a veinte salarios mínimos legales mensuales vigentes en Colombia. 
Aunque el Decreto 196 fue modificado por la Ley 583, el primero fue reglamentado por el Decreto 765 de 1977, normatividad que aún se encuentra vigente en el ordenamiento jurídico colombiano. Este decreto consagra los requisitos que deben cumplir los consultorios jurídicos para su funcionamiento, y la obligación de los estudiantes de los dos últimos años de la carrera de Derecho de trabajar al servicio del consultorio jurídico por lo menos durante dos semestres atendiendo los casos que les sean asignados, en concordancia con las competencias asignadas por la hoy vigente Ley 583.

Con la entrada en vigor de la Constitución Política de 1991, se le dio trascendental relevancia al derecho de igualdad y al principio de dignidad humana como pilares del Estado social de derecho y «la base de un conjunto de derechos sociales y económicos que buscan la consecución de la justicia social» (Monroy Álvarez, 2006: 168). Esto implica por parte de los consultorios jurídicos una responsabilidad que no sólo se enmarca en la representación legal o la consultoría jurídica gratuita, sino también en actividades de pedagogía jurídica, generación de espacios que promuevan la participación ciudadana y la vinculación a proyectos que fomenten los derechos fundamentales y constitucionales de los ciudadanos. De esta manera,

los consultorios jurídicos no pueden ser pensados únicamente con relación a las funciones que les ha otorgado la ley como «abogados de pobres», sino que su función social debe ser articulada con la promoción de los derechos humanos y fundamentales dentro de lo de su competencia, materializados en acciones transformadoras que atiendan las necesidades de los usuarios (Guevara Flórez, 2020).

En este sentido, el mayor campo de acción de los consultorios jurídicos del país se enmarca en la atención mecánica de los estudiantes a los usuarios; sin embargo, los estudiantes son guiados por docentes que en su mayoría continúan siendo litigantes y brindan asesoría un número limitado de horas a la semana sin buscar salidas novedosas a casos complejos, y en su lugar continúan con prácticas ritualistas, rutinarias y legalistas (Recalde, Luna Blanco y Bonilla Maldonado, 2017: 45). Esta cuestión ha dificultado la implementación de soluciones innovadoras que repercutan en los procesos de enseñanza y aprendizaje y en los objetivos y la función social que debe cumplir el consultorio jurídico.

De acuerdo con la investigación de Quintero, Recalde y Urriago (2012), las personas que se encuentran en una situación económica precaria enfrentan mayores obstáculos para acceder a la justicia que quienes cuentan con los medios económicos para contratar a un abogado. Por ello, insisten en que los consultorios jurídicos juegan un papel relevante en la solución de las dificultades en las que se encuentran de manera cotidiana y requieren asesoría o acompañamiento legal.

En consecuencia, es de resaltar que, «a pesar de que en Colombia se está apenas en el camino para aprovechar todas las posibilidades y oportunidades que ofrecen los consultorios jurídicos, y que no se han encontrado textos científicos que reflejen 
la aplicación de acciones de mejora para la prestación del servicio» (Guevara Flórez, 2020), los consultorios de las facultades de Derecho cumplen un papel fundamental para aquellas personas que no cuentan con los recursos económicos para contratar un abogado.

\section{Implementación de TIC}

El uso de las TIC para prestar los servicios de los consultorios jurídicos es una propuesta reciente. Sin embargo, se han encontrado algunos artículos científicos y textos referidos a su implementación. A nivel internacional, el artículo de Thanaraj y Sales (2015) menciona la clínica jurídica virtual en la Universidad de Cumbria (Reino Unido), bajo la modalidad de una oficina virtual para que los estudiantes hagan sus prácticas con personas que no cuentan con los recursos económicos para contratar a un abogado.

El servicio que ofrecen es completamente virtual. En ese caso, conscientes de que no todas las personas cuentan con el conocimiento necesario para navegar en un ambiente de esta naturaleza, menciona el documento que es decisión de los usuarios si este tipo de servicio es el adecuado para ellos. En consecuencia, los interesados en el servicio tendrán a su disposición los términos y condiciones de éste, los cuales deberán leer y aceptar de manera previa. Los asesores recibirán notificación de una nueva consulta y podrán aceptarla o rechazarla dentro del término de tres días hábiles. En caso de ser aceptada, el usuario recibirá a su vez un usuario y contraseña para acceder al sistema. Todo el proceso se hará a través de la plataforma digital.

Se hicieron pruebas piloto que permitieron mejorar el prototipo, las que arrojaron como resultado que la seguridad, confidencialidad y encriptación del portal deben ser prioridad; además, las herramientas de comunicación y el progreso de los casos, así como subir y descargar documentos, son aspectos claves para su funcionamiento. Los usuarios siempre tienen acceso a los documentos que suben o los documentos preparados por los estudiantes o asesores, que estarán disponibles para hacerles comentarios o retroalimentación.

Las comunicaciones entre usuario y estudiante quedan grabadas y almacenadas con la fecha y hora en que tuvieron lugar. Los documentos tendrán la información de cuándo fueron subidos, cuándo fue su última edición y quién la hizo. Todos los datos serán almacenados y sujetos a regulares copias de respaldo (backup). Además, consideraron pertinente la inclusión de un video tutorial para el uso del sitio.

De acuerdo con el documento, se busca que el estudiante y futuro abogado conozca las herramientas que podrá utilizar en el futuro ejercicio profesional, mas no está pensada para solucionar aspectos sociales de quienes usan el servicio. Es de anotar que cuando se hace una búsqueda en línea de la clínica jurídica virtual de Cumbria, no se encuentra ningún acceso a ella, y el enlace disponible en el artículo dirige a una página totalmente diferente. 
En lo concerniente a Colombia, se encontraron dos artículos científicos publicados en revistas indexadas que comprenden los resultados de una investigación de maestría en Informática, titulada «Propuesta de un modelo conceptual de sistema de información para el consultorio jurídico de la UIS» (González, Gómez y González Noriega, 2007). Estos documentos dan cuenta de un prototipo diseñado para el consultorio jurídico de la Universidad Industrial de Santander (Colombia), que buscaba hacer más eficiente la gestión de los procesos al interior de la institución.

En dicha investigación se utilizó una metodología de sistemas blandos, pues se consideró que era la adecuada, toda vez que proporcionaba los elementos para llevar a cabo una investigación en que la realidad es susceptible de ser interpretada de diferentes maneras por los sujetos que interactúan en ella frente a los objetivos y propósitos de la organización; de esta manera, se logra enfrentar la situación real con el sistema pertinente para los propósitos organizacionales e identificar una posibilidad de mejora.

Con esta propuesta, se buscó mejorar la eficiencia y tener un mayor control y supervisión sobre las actividades que se desarrollaban en el consultorio jurídico de la IUS, lo que tuvo como resultado la automatización de información, como: i) verificación de posibilidades de atención al usuario, registro de usuarios, selección de áreas de atención, registro de datos personales de usuario y asignación de estudiantes; ii) reparto de asesoría, registro del concepto brindado al usuario, registro de documentos recibidos del usuario, registro y programación de citas con el usuario; iii) registro de la actuación a llevar a cabo con el usuario, consulta de estado de actividades y citas programadas, registro de actuaciones, actividades y de la finalización del proceso.

De estos procesos se obtuvieron los siguientes indicadores: número de estudiantes que asistieron a charlas introductorias y a capacitaciones, número de consultas registrada, consultas por áreas, por asunto, por estrato, por día de la semana, por estudiante, número de conciliaciones acompañadas por estudiante, número de derechos de petición por estudiante, número de negocios iniciados, número de negocios terminados, número de tutelas, número de derechos de petición, número de trámites procesales iniciados, número de trámites procesales abandonados y número de conciliaciones logradas, entre otros (González y otros, 2007: 18).

Dentro de los resultados de la investigación, se tiene que se logró un mayor conocimiento de los propósitos del consultorio jurídico, se formalizaron actividades del consultorio a través de sistemas de actividad humanas; se mejoró el seguimiento y control de las actividades del consultorio, así como la administración de prácticas y talento humano; se empezaron a hacer trabajos interdisciplinarios y se reconocieron las ventajas que ofrecen las tecnologías de la información para este tipo de procesos (González, Gómez y González Noriega, 2007: 7).

Es de anotar que la investigación tenía como propósito la creación de un prototipo para la gestión interna de los procesos del consultorio jurídico, mas no estuvo 
encaminada a la interacción institucional con los usuarios a través del mundo digital; por lo tanto, ambos documentos científicos presentaron resultados que dan cuenta de este proceso. En conclusión, este tipo de proyectos, si bien tienen repercusión en la gestión de consultas al interior de los consultorios jurídicos, no tienen ningún impacto directo en la comunidad que atienden, así como tampoco inciden en la promoción de la justicia social.

Por otro lado, se encontró un trabajo monográfico para acceder al título de abogada de Ramírez Meza (2011), en el que se planteó la implementación de un sistema virtual para el consultorio jurídico de San Andrés de Tumaco, Colombia. La autora propone la incorporación del consultorio jurídico virtual en el municipio de Tumaco desde la Casa de Justicia, al que podrán acercarse los usuarios para hacer uso de equipos y conectarse con el consultorio jurídico, para promover el acceso a la justicia. Indica que se podrá hacer uso del servicio a través de videollamada desde la casa de justicia, mientras el estudiante que atiende podrá llenar un formulario web. Si es necesario, el usuario podrá escanear los documentos requeridos para completar la consulta (Ramírez Meza, 2011: 45-46).

Esta idea, de acuerdo con la investigación, es una réplica del consultorio jurídico virtual que tiene en la actualidad la Universidad de San Buenaventura de Cali. No obstante, en el trabajo de grado se observa que, para la confección del consultorio, sólo se hizo una descripción de la situación que para el momento vivía la comunidad tumaqueña, sin verificar cuáles eran las problemáticas más recurrentes o la caracterización de la población a partir de la recolección de datos para la creación y posterior implementación del servicio. Ésta resulta una idea interesante, pues San Andrés de Tumaco es un municipio en que las ciudades capitales con consultorios jurídicos disponibles más cercanos son Pasto a $300 \mathrm{~km}$ y Cali a $669 \mathrm{~km}$. Esto significa que la implementación de este modelo daría atención a una población aproximada de más de 160.000 habitantes, lo que facilitaría la materialización de la justicia social. No obstante, cabe anotar que hoy no existen sitios web que den cuenta de la implementación y posible mejora de tal servicio en la Casa de Justicia de Tumaco.

Al verificar el consultorio jurídico virtual de la Universidad de San Buenaventura de Cali, de donde se origina la idea de la abogada, se observa que cuentan con un formulario que debe ser diligenciado por el usuario, en el que éste debe suministrar unos datos básicos y luego hacer la consulta de manera escrita.

En Colombia existen 116 instituciones de educación superior que cuentan con facultad de Derecho ${ }^{24}$ y 189 programas activos en el país; ${ }^{25}$ de éstas, 99 prestan el ser-

24. "Las mejores universidades de Colombia en derecho», Dinero, 25 de mayo de 2017, disponible en https://bit.ly/3lizp3x.

25. «Sistema Nacional de la Educación Superior», Ministerio de Educación Nacional de Colombia, disponible en https://bit.ly/31dXXyD. 
vicio de consultorio jurídico de manera presencial y 16 tanto de manera presencial como virtual.

El Ministerio de Justicia y del Derecho manifestó su interés en trabajar en conjunto con los consultorios jurídicos, dado que son una importante herramienta para la administración de justicia. En consecuencia, buscan que los consultorios atiendan las necesidades jurídicas y sociales actuales, incluyendo dentro de esta aproximación las nuevas tecnologías de la información y la comunicación. Es así como, entre otras iniciativas, se encuentra la herramienta Legal App. ${ }^{26}$

Legal App es una herramienta tecnológica del Ministerio que permite a los usuarios agendar citas de manera virtual con los consultorios jurídicos que cuentan con esta posibilidad. La herramienta puede ser utilizada a través del sitio web o de una aplicación en dispositivos electrónicos, que además del agendamiento de citas, permite informarse sobre términos jurídicos, temas más consultados, enlaces de interés y un directorio de direcciones de instituciones de atención jurídica a los ciudadanos.

Sumado a esto, Legal App cuenta con la opción para acceder a los consultorios jurídicos que existen por departamentos y municipios, discriminando aquellos consultorios jurídicos que cuentan con modalidad virtual. Estos últimos, de acuerdo con la consulta en el sitio web del 10 de junio de 2020, ascienden a dieciséis, de los cuales seis consisten en el diligenciamiento de un formulario en el que se solicitan datos básicos de los usuarios y una breve descripción del caso; tres enlaces tienen la posibilidad de hacer consultas anónimas o con registro en un chat, mientras que otros tres arrojan un error en la página cuando se les hace clic; por último, cuatro enlaces direccionan a la página del consultorio, mas no es visible el enlace para acceder a la versión virtual.

Recalde, Luna Blanco y Bonilla Maldonado (2017) sugieren que los consultorios jurídicos deben hacer una atención integral a los usuarios en situación de vulnerabilidad, implementando un sistema de información en el que se encuentre la resolución de casos complejos (sistema autónomo) y que permita hacer seguimiento a los estudiantes que atienden las consultas. Además, se recomienda la utilización de medios electrónicos que faciliten la sistematización y salvaguarda de la información de los usuarios. Con ello, se podría garantizar, a través del consultorio jurídico, la protección de derechos humanos como el derecho a la intimidad, a la protección de datos personales y el debido proceso, entre otros. Respecto de la utilización de sistemas digitales para la gestión interna de procesos, la mayor parte de los consultorios jurídicos utilizan diversas herramientas como Lex o Visto Bueno.

Ahora, en lo que tiene que ver con la atención a usuarios a través de medios digitales, de acuerdo con los mencionados autores, el 10,8\% de los consultorios jurídicos

26. Carlos Mario Molina Betancur, «¿El fin de los consultorios jurídicos en las facultades de Derecho?», Ámbito Jurídico, 10 de marzo de 2016, disponible en https://bit.ly/2GtURyZ. 
en Colombia tienen la modalidad virtual, lo que permite que el número promedio de usuarios atendidos sea el doble. Esto quiere decir que mientras un consultorio jurídico en promedio atiende entre 120 y 550 usuarios al mes, quienes cuentan con la modalidad virtual podrían atender hasta cerca de 1.100 usuarios (Recalde, Luna Blanco y Bonilla Maldonado, 2017: 48-49).

En este punto se debe destacar la alianza estratégica entre la Gobernación de Nariño y la Universidad de Nariño en 2016, llamada «Consultorios jurídicos virtuales», mediante la cual estas dos entidades unieron esfuerzos para llevar el consultorio jurídico a todos los municipios del departamento de Nariño, y atender así a personas vulnerables y de bajos recursos económicos sin necesidad de desplazamiento a la universidad en Pasto. Las consultas se pueden hacer mediante un chat con o sin registro. Aquellas personas que no cuentan con el servicio de internet pueden acercarse a un punto de vive digital, ${ }^{27}$ en el que disponen de dispositivos electrónicos y acceso a la red para hacer la consulta jurídica de manera virtual. Este programa reporta 6.206 consultas solicitadas, 13.505 ingresos al sistema y 7.866 atenciones. ${ }^{28}$

En lo que respecta a la declaratoria del estado de emergencia ambiental, social y económica en Colombia como consecuencia del covid-19, se determinó que las instituciones de educación superior - tanto del sector público como del privado- deberían continuar con el desarrollo de las actividades académicas usando las tecnologías de la información y la comunicación. Esto trajo como consecuencia la suspensión de la prestación del servicio de la gran mayoría de los consultorios jurídicos en Colombia. A pesar de que antes de la declaratoria de emergencia algunos consultorios ya contaban con la modalidad virtual, esto ha supuesto todo un reto para las instituciones de educación superior y la prestación de servicios jurídicos gratuitos mediados por la virtualidad.

Ante la imposibilidad de prestar el servicio en modalidad presencial, se indagó en los consultorios jurídicos de las 84 facultades de Derecho conectadas a la Asociación Colombiana de Facultad de Derecho (ACOFADE), con el fin de verificar la situación actual y las condiciones de prestación del servicio. Los resultados aparecen en la figura 2.

De acuerdo con la indagación, se encontró que el 22\% de los consultorios jurídicos cuenta con formularios que los usuarios deben diligenciar para que sus requerimien-

27. «Este proyecto surgió con el objetivo de instalar y operar centros de acceso comunitario a internet en zonas vulnerables de cabeceras municipales del país, permitiendo a más de 1.80o.ooo colombianos acceder a internet, entretenerse, hacer trámites y servicios en línea, y capacitarse en contenidos como alfabetización digital básica, ofimática, redes sociales para el emprendimiento, educación virtual y desarrollo de contenidos digitales». «Puntos digitales», Ministerio de Tecnologías de la Información y las Comunicaciones, disponible en https://bit.ly/36p21zO.

28. «Servicios que ofrecen los consultorios jurídicos virtuales», Gobernación de Nariño, disponible en https://bit.ly/36nChnp. 


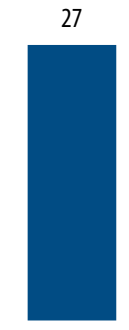

Presencial

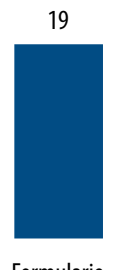

Formulario

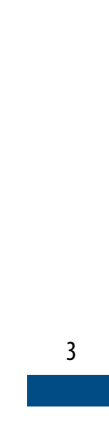

Chat

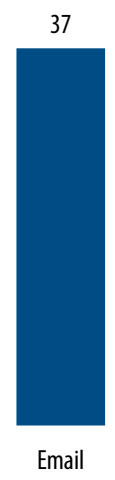

Videollamada Email

Figura 2. Modalidades de prestación del servicio de los consultorios jurídicos. Fuente: Elaboración propia.

tos sean atendidos; el $4 \%$ tiene un sistema más ágil, que consiste en la posibilidad de chatear con el estudiante y atender las consultas en tiempo real, al igual que uno de los consultorios, que con sólo dar un clic se direcciona a una página de Google Hangouts para atender al usuario a través de videollamada. Sumado a esto, se encontró que el $43 \%$ de los consultorios jurídicos cuentan con un correo electrónico al que se pueden dirigir las consultas. Con todo, al ingresar a los sitios web de las instituciones de educación superior que sirvieron de muestra para la indagatoria, no se evidenciaron campañas de sensibilización que promovieran el uso de estas nuevas herramientas para las consultas jurídicas.

Por último, las cifras muestran que el 31\% de los consultorios jurídicos sólo prestan el servicio de manera presencial y, por lo tanto, cuando se inició la pandemia se suspendió por completo la atención a los usuarios. En su lugar, se optó por hacer audiencias simuladas, desarrollar casos prácticos que incluyen elaborar demandas, derechos de petición y acciones de tutela, entre otros. ${ }^{29}$ Si bien fue una solución al problema de la interrupción de la práctica para los estudiantes de Derecho, estas instituciones no propusieron una solución que permitiera a los usuarios seguir haciendo consultas y, en consecuencia, cumplir con una de sus principales funciones, la promoción de la justicia social.

Respecto de las consultas y procesos que ya se habían recibido y se estaban tramitando, se dio respuesta a las primeras, y los segundos se siguieron impulsando en la rama Judicial, siempre y cuando fuesen procesos que estuviesen en las excepciones contempladas por los Acuerdos del Consejo Superior de la Judicatura. ${ }^{30}$

Es del caso mencionar que el estado de excepción trajo consigo una crisis social y económica que se tradujo en el aumento de problemáticas jurídicas como el cierre

29. Jinyola Blanco Rodríguez, «La reinvención de la enseñanza jurídica», Ámbito Jurídico, 31 de mayo de 2020, disponible en https://bit.ly/36noBsr.

30. «La reinvención...». 
definitivo de empresas y negocios, despidos masivos y suspensión de contratos laborales, lo que a su vez ha traído como consecuencia atrasos en el pago de cánones de arrendamiento, créditos y préstamos ante entidades financieras, además del aumento de la violencia intrafamiliar en un porcentaje de hasta el $200 \%$ en algunas ciudades. ${ }^{31}$ Estas circunstancias implican que se susciten una serie de inquietudes en quienes han sido víctimas directas de las consecuencias de las medidas de confinamiento, y que por regla general se encuentran en situación de vulnerabilidad por su condición económica, es decir, los beneficiarios directos de los servicios de los consultorios jurídicos.

Ante tales condiciones críticas, los consultorios jurídicos tienen una responsabilidad fundamental en la promoción de la justicia social, pues las actuales circunstancias económicas, de sanidad y sociales han disparado los índices de personas en estado de vulnerabilidad al estar desempleadas y, por consiguiente, no contar con los recursos económicos suficientes para su congrua subsistencia. Esto pone a los consultorios jurídicos en un lugar clave, en el que deberán plantear unas líneas de acción para la prestación de sus servicios en modalidad virtual, con el fin de dar respuesta a las necesidades de los usuarios e incluso ampliar su cobertura. Con todo, estas estrategias deberán incluir un estudio de las condiciones socioeconómicas de los usuarios y del nivel de penetración de las TIC en su entorno social, con el objetivo de que las estrategias se adecúen a sus necesidades. Así, la identificación de las condiciones económicas, accesibilidad al internet y familiaridad con el manejo de herramientas TIC facilitará la implementación de estrategias adecuadas que redunden en la efectiva utilización del servicio.

Es importante tener en cuenta que en la actualidad los consultorios jurídicos no atienden público en los períodos de vacaciones académicas, que en Colombia están establecidas entre junio y julio y entre diciembre y enero, puesto que sólo funcionan en los periodos académicos en que hay estudiantes cursando esta asignatura de práctica. Esto supone un reto para las facultades de Derecho, pues deberán buscar y aplicar estrategias que eviten la interrupción del servicio, teniendo en cuenta además que en la rama Judicial, la vacancia o periodo de vacaciones de los funcionarios opera únicamente por quince días hábiles entre diciembre y enero de cada año.

Tampoco se debe perder de vista que, como ya se ha dicho, las decisiones de las altas autoridades en materia de administración de justicia en Colombia han tomado decisiones que ponen en jaque sobre todo a personas que no cuentan con los recursos económicos suficientes para adquirir los dispositivos electrónicos, la contratación de servicios de internet, e incluso a quienes no han desarrollado las habilidades y destrezas necesarias para su manejo. En este punto, cabe recordar que esto tendrá

31. Ludys Ovalle Jácome, «Incrementó en 200 por ciento la violencia intrafamiliar en Valledupar», $E l$ Tiempo, 12 de mayo de 2020, disponible en https://bit.ly/2G6RTB1. 
un fuerte impacto en los consultorios jurídicos y sus usuarios, pues si bien es posible que las instituciones de educación superior cuenten con las facilidades técnicas para la realización de trámites judiciales de manera digital, la principal característica de los usuarios es su paupérrima situación económica, que en muchos casos no les permitirá acceder a este tipo de herramientas. Es decir, se deberán adelantar estrategias conjuntas para el acceso a los servicios de administración de justicia para personas de escasos recursos económicos, que incluyan zonas de acceso gratuito a internet, capacitación y sensibilización para el uso de herramientas TIC.

Por último, no está de más mencionar que el Ministerio de Justicia y del Derecho ha dejado en manos de la autonomía universitaria las estrategias para la prestación del servicio de los consultorios jurídicos; de ahí que no haya tenido pronunciamientos oficiales respecto del papel que vienen desempeñando estas instituciones en la época de pandemia, así como tampoco recomendaciones de estrategias concretas para permitir y simplificar el acceso de los usuarios a los servicios gratuitos que potencien uno de sus principales objetivos: la promoción de la justicia social.

\section{Conclusiones}

El mundo vive un crecimiento acelerado y la inclusión de las TIC en las dinámicas del diario vivir no son la excepción. Todos los días hay más penetración de internet en las diferentes comunidades. En efecto, como se pudo vislumbrar a lo largo de este artículo, cada año se viene promoviendo la prestación de servicios sociales a través de medios digitales.

Diferentes autores han indicado que las TIC deben ser utilizadas como una herramienta para la inclusión social. No obstante, la incorporación de plataformas virtuales sin las adecuadas políticas que promuevan su empleo, en lugar de incentivar la inclusión, provocarán la exclusión de aquellos miembros de la comunidad que no estén familiarizados con su uso. Para que la brecha digital pueda ser disminuida hará falta no sólo voluntad política, sino también la asignación de recursos, un personal destinado a la implementación, seguimiento y supervisión de la herramienta y un grupo capacitado que sirva para adiestrar a los usuarios en su utilización.

Se encontró que, a pesar de la existencia de normativas para la inserción de las TIC en el sector justicia, no existe una política pública que relacione la inclusión social vinculada a la prestación de servicios jurídicos para satisfacer las necesidades legales de la comunidad. Con el advenimiento de la crisis social, económica y sanitaria producida por la pandemia de covid-19, se evidenció la necesidad de la puesta en marcha de acciones concretas para la prestación de servicios jurídicos. No obstante, la normatividad emitida por las altas autoridades administrativas y judiciales en Colombia deja más retos que soluciones. La nueva agenda TIC debe procurar la satisfacción de los requerimientos de la comunidad en el ámbito jurídico para la solución de 
las problemáticas que los aquejan, en condiciones de igualdad y gratuidad, tal como lo manda la Constitución Política y la ley en Colombia.

El consultorio jurídico contribuye a ese mandato de gratuidad en el acceso a la administración de justicia y, en ese sentido, busca básicamente dos cosas: la enseñanza experiencial y la promoción de la justicia social. En Colombia, por mandato de la ley, los consultorios prestan un servicio social que es utilizado por gran cantidad de personas pertenecientes a los estratos socioeconómicos más desfavorecidos. La crisis global de 2020 ha mostrado que el consultorio jurídico no puede ser ajeno a los avances tecnológicos que se han ido dando, y debe apuntar a la creación de una nueva dinámica social en que la utilización de las TIC se convierta en una herramienta cotidiana para acceder a servicios de consultoría y asesoría jurídica al alcance de un clic o toque en un dispositivo electrónico.

Se ha encontrado que algunos consultorios jurídicos en Colombia tienen modalidad virtual; sin embargo, en su gran mayoría éstos se limitan sólo al diligenciamiento de formularios, chats o el envío de correos electrónicos con las consultas formuladas por los usuarios. La implementación de las herramientas TIC debe tomar en cuenta las condiciones sociales y económicas de los usuarios, incluyendo elementos de interactividad que faciliten la recepción y resolución de las consultas.

La investigación de Recalde, Luna Blanco y Bonilla Maldonado (2017) afirmó que con la modalidad virtual se amplía la cobertura al doble de usuarios. Incluso, se recopiló información que evidencia la atención de más de 6.000 consultas bajo esta modalidad en tan sólo uno de los 32 departamentos de Colombia. Esta información resulta relevante, pues, así como se ha ampliado la cantidad de usuarios atendidos con estos sistemas básicos, una investigación juiciosa podrá arrojar resultados para: i) construir una herramienta que atienda el perfil y las necesidades de los usuarios; ii) promover el uso de estas herramientas; y iii) construir una herramienta interactiva e incluso autónoma para la solución de inquietudes jurídicas.

Si bien existen algunos procedimientos que seguirán requiriendo presencialidad, es una formalidad que se ha ido eliminando para la gestión de algunos trámites. Es decir, a través de determinadas herramientas tecnológicas, se han venido facilitando dinámicas que mejoran la calidad de vida de las personas sin importar su condición social, económica, cultural, étnica, física ni su edad, lo cual acerca los servicios públicos a la ciudadanía. Sin embargo, para saber hasta qué nivel es pertinente la implementación de una herramienta tecnológica en el consultorio jurídico, será necesario determinar los procesos que se hacen, clasificarlos y caracterizarlos, así como identificar el perfil de sus usuarios para, finalmente, definir cómo y hasta qué nivel se podrán digitalizar los servicios para atender las necesidades de la comunidad, lo que en la actualidad ya no es una opción, sino una necesidad.

Por último - pero no menos importante-, será necesaria la creación de una política pública que se materialice a través de acciones y estrategias concretas para la pro- 
moción del uso de las herramientas tecnológicas, pues por sí solas y sin la adecuada divulgación y capacitación, la brecha digital podría ampliarse en lugar de estrecharse. Para dicho propósito, se insiste en que se deberá estudiar el contexto incluyendo a la comunidad que se pretende impactar, y la pertinencia de dicha política en el marco de instrumentos internacionales para el desarrollo, así como las políticas de inclusión y promoción de TIC en la legislación doméstica, depositada en leyes, decretos, ordenanzas y acuerdos del nivel nacional, departamental y municipal.

\section{Referencias}

BARtoli, Clelia (2016). «Legal clinics in Europe: For a commitment of higher education in social justice». Diritto \& Questioni Pubbliche, 1. Disponible en https://bit. ly/2GnNSYH.

Bonilla Maldonado, Daniel (2018). «Consultorios jurídicos: Educación para la democracia». En Abogados y justicia social: Derecho de interés público y clínicas jurídicas (pp.17-110). Bogotá: Uniandes, Siglo del Hombre.

-. (2013). «El formalismo jurídico, la educación jurídica y la práctica profesional del derecho en Latinoamérica». En Helena Olea Rodríguez (editora), Derecho y pueblo mapuche (pp. 259-302). Santiago: Universidad Diego Portales.

Caballero, José Antonio, Carlos Gregorio de Gràcia y Linn Hammergren (2011). Buenas prácticas para la implementación de soluciones tecnológicas en la administración de justicia: Conclusiones preliminares y documentos para el debate del Seminario sobre Tendencias Recientes y Buenas Prácticas en la aplicación de Tecnologías Digitales al Proceso Judicial.

Flórez Buitrago, Leidy Diana, Carolina Ramírez y Susana Ramírez (2016). «Las TIC como herramientas de inclusión social». 3 C TIC, 5 (1): 54-67. DOI: 10.17993/3ctic.2016.51.54-67.

Frank, Jerome (1947). «A plea for Lawyer-Schools». The Yale Law Journal, 56 (8): 1.303-1.344. DOI: $10.2307 / 793068$.

González, Mayda Patricia, Luis Carlos Gómez, Ernesto Galvis Lista, Mariutzi Alexandra Osorio y Olga Cecilia González Noriega (2007). «Modelamiento conceptual e implementación de una plataforma teamware para el soporte de las actividades del Consultorio Jurídico UIS». UIS Ingenierías, 6 (1): 9-23. Disponible en https://bit.ly/33hUIYs.

González, Mayda Patricia, Luis Carlos Gómez y Olga Cecilia González Noriega (2007). «Propuesta de un modelo conceptual de sistema de información para el consultorio jurídico de la UIS». Scientia et Technica, 1 (37): 443-448. Disponible en https://bit.ly/2Shm6Q4.

Guevara Flórez, Lady Juliana (2020). «Modelo de gestión digital para el consultorio jurídico Marceliano Vélez Barreneche: Un estudio de las necesidades de los 
usuarios del municipio de Envigado, Colombia». Tesis para postular al grado de doctora en Proyectos. Universidad Internacional Iberoamericana UNINI, México. Jiménez Gómez, Carlos E. (2014). «Desafíos de la modernización de la justicia en tiempos del Gobierno abierto». Revista Digital de Derecho Administrativo, 12: 225239. Disponible en https://bit.ly/3cNGXDZ.

Lillo Lobos, Ricardo (2010). «El uso de nuevas tecnologías en el sistema judicial: Experiencias y precauciones». Disponible en https://bit.ly/2EQlkgN.

Molina Betancur, Carlos Mario. (2016). «¿El fin de los consultorios jurídicos en las facultades de Derecho?», Ámbito Jurídico, 10 de marzo de 2016, disponible en https://bit.ly/2GtURyZ

Monroy Álvarez, Silvia (2006). «Holismo e individualismo durante el ejercicio de la ciudadanía en el consultorio jurídico de Fredonia, Antioquia». Universitas $\mathrm{Hu}$ manística, 61: 163-182. Disponible en http://ref.scielo.org/vft2cf.

Pérez Serrano, Gloria y Sarrate Capdevila, María Luisa Pérez, G. \& Sarrate, (2011). «Las TIC promotoras de inclusión social. Revista Española de Pedagogía». Año LXIX, (249), mayo- agosto 2011: 237-254. Disponible en: https://dialnet.unirioja. es/servlet/articulo? codigo $=3616802$

Quintero, Diana Patricia, Gabriela Recalde y Juan Fernando Urriago (2012). «El acceso a una justicia diferencial la situación de población en vulnerabilidad socioeconómica en Cali». Estudios de Derecho, 69 (154): 73-97. Disponible en https:// bit.ly/3jxnrOA.

Ramírez Meza, Loren Zulima (2011). «Diseño de implementación del sistema del consultorio jurídico virtual para el municipio de San Andrés de Tumaco». Tesis de grado para optar al título de abogada. Universidad de San Buenaventura-Cali, Colombia.

ReCAlDE, Gabriela, Tania Luna Blanco y Daniel Bonilla Maldonado (2017). «Justicia de pobres: Una genealogía de los consultorios jurídicos en Colombia». Revista de Derecho, 47: 1-72. Disponible en https://bit.ly/36mZgid.

RodríGuez, Paola Andrea (2012). «Límites y posibilidades de las TIC en la inclusión social». En Tecnologías de la información para la inclusión social: Una apuesta por la diversidad. Bogotá: Colombia Digital.

SÁnchez DuARTE, Esmeralda (2008). "Las tecnologías de información y comunicación (TIC) desde una perspectiva social». Revista Educare, 12: 155-162. DOI: 10.15359/ree.12-Ext.13.

Silva, Juan y Marcela Romero (2014). «La virtualidad una oportunidad para innovar en educación: Un modelo para el diseño de entornos virtuales de aprendizaje». $D i$ dasc@lia: Didáctica y Educación, 5 (1): 1-23. Disponible en https://bit.ly/2Gu8azr.

Sourdin, Tania (2015). «Justice and technological Innovation». Journal of Judicial Administration, 25 (2). Disponible en https://bit.ly/2G7MGsI. 
ThanaraJ, Ann y Michael Sales (2015). «Lawyering in a digital age: A practice report. Introducing the virtual law clinic at Cumbria». International Journal of Clinical Legal Education, 22 (3): 1-29. DOI: 10.19164/ijcle.v22i3.471.

Vallejo, Eugenia (2012). «Hablemos de inclusión social». En Tecnologías de la información para la inclusión social: Una apuesta por la diversidad. Bogotá: Colombia Digital.

\section{Sobre los autores}

LAdy Juliana Guevara Flórez es abogada y especialista en derecho administrativo laboral de la Institución Universitaria de Envigado, Colombia. Candidata a doctora en Proyectos de la Universidad Internacional Iberoamericana de México. Docente de tiempo completo en la Facultad de Ciencias Jurídicas y Políticas de la Institución Universitaria de Envigado. Su correo electrónico es ljguevara@correo.iue.edu.co. https://orcid.org/oooo-0001-5778-799x.

Carlos Eduardo Uc Ríos es ingeniero en Comunicaciones y Electrónica de la Universidad Autónoma de Campeche, México. Maestro y doctor en Ciencias en el área de Ingeniería Eléctrica opción Telecomunicaciones del Centro de Investigación y Estudios Avanzados del IPN, México. Profesor e investigador de tiempo completo en la Facultad de Ingeniería de la Universidad Autónoma de Campeche. Su correo electrónico es carloeuc@uacam.mx. (1D https://orcid.org/oooo-0003-1321-019x. 


\title{
REVISTA CHILENA DE DERECHO Y TECNOLOGÍA
}

La Revista de Chilena de Derecho y Tecnología es una publicación académica semestral del Centro de Estudios en Derecho Informático de la Facultad de Derecho de la Universidad de Chile, que tiene por objeto difundir en la comunidad jurídica los elementos necesarios para analizar y comprender los alcances y efectos que el desarrollo tecnológico y cultural han producido en la sociedad, especialmente su impacto en la ciencia jurídica.

\author{
EDITOR GENERAL \\ Daniel Álvarez Valenzuela \\ (dalvarez@derecho.uchile.cl) \\ SITIO WEB \\ rchdt.uchile.cl \\ CORREO ELECTRÓNICO \\ rchdt@derecho.uchile.cl \\ LICENCIA DE ESTE ARTÍCULO \\ Creative Commons Atribución Compartir Igual 4.o Internacional
}

\begin{abstract}
La edición de textos, el diseño editorial
y la conversión a formatos electrónicos de este artículo

estuvieron a cargo de Tipográfica

(www.tipografica.io).
\end{abstract}

